\title{
QUEM SOU EU PARA DISCORDAR DE UM MINISTRO DO STF? O ENSINO DO DIREITO ENTRE ARGUMENTO DE AUTORIDADE E LIVRE DEBATE DE IDEIAS
}

\author{
Virgílio Afonso da Silva e Daniel Wei Liang Wang*
}

\section{RESUMO}

ESTE ARTIGO TEM COMO OBJETIVO NARRAR UMA EXPERIÊNCIA CONCRETA COM AULAS PARTICIPATIVAS. O QUE SE PRETENDE É, ENTRE OUTRAS COISAS, DEMONSTRAR QUE NEM SEMPRE SÃO NECESSÁRIAS REFORMULAÇÕES RADICAIS NA METODOLOGIA DO ENSINO JURÍDICO PARA QUE RESULTADOS POSITIVOS SEJAM alcançados. Algumas das formas tradicionaIS DE ENSINO - NO CASO EM QUESTÃO, OS SEMINÁRIOS - ÀS VEZES NÃO PRODUZEM OS EFEITOS DESEJADOS, POR DEFICIÊNCIAS NO PLANEJAMENTO OU POR REPRODUZIREM VÍCIOS DO ENSINO JURÍDICO, COMO: ENSINO NÃO PARTICIPATIVO; FOCO NO ARGUMENTO DE AUTORIDADE; MUITA EXPOSICCÃO E POUCO DEBATE; FALTA DE INCENTIVO A POSTURAS CRÍTICAS ETC. A REPRODUÇ̃̃O DESSES VÍCIOS, ALIADA AO FATO DE QUE, NOS SEMINÁRIOS, MUITAS VEZES O PROFESSOR ESTÁ AUSENTE, PARECE-NOS SER A CAUSA DA PERCEPÇÃO GENERALIZADA DE QUE AULAS DE SEMINÁRIOS SÃO UMA FORMA MENOS IMPORTANTE DE APRENDIZADO. NOSSA EXPERIÊNCIA TEM DEMONSTRADO QUE ESSE CENÁRIO PODE SER MUITO DIFERENTE, SE ALGUNS CUIDADOS FOREM TOMADOS.

\section{PALAVRAS-CHAVE}

ENSINO JURÍDICO; METODOLOGIA; DIREITOS FUNDAMENTAIS; JURISPRUDÊNCIA; SEMINÁRIOS.

\section{APRESENTAÇÃo}

A indagação que dá título a este artigo foi feita, timidamente, por um aluno durante a apresentação do primeiro seminário do curso de direitos fundamentais, no curso de graduação da Faculdade de Direito da Universidade de São Paulo. Sua escolha como título tem uma razão simples. A pergunta reflete alguns dos vícios mais graves

\begin{abstract}
THE AIM OF THIS PAPER IS TO NARRATE AN EXPERIENCE WITH PARTICIPATIVE CLASSES. WE ARGUE THAT RADICAL CHANGES IN THE CURRENT METHODS OF LEGAL EDUCATION ARE NOT ALWAYS NECESSARY IN ORDER TO ACHIEVE POSITIVE OUTCOMES. SOMETIMES THE PARTICIPATIVE METHODS ALREADY USED IN BRAZILIAN LEGAL EDUCATION - WE FOCUS ON SEMINARS FAIL TO LEAD TO GOOD RESULTS EITHER DUE TO DEFICIENCIES IN PLANNING, OR BECAUSE THEY TEND TO REPLICATE THE MOST COMMON PROBLEMS ASSOCIATED WITH NON-PARTICIPATIVE METHODS, SUCH AS: FOCUSING ON ARGUMENTS FROM AUTHORITY; EXCESS OF LECTURING AND LACK OF DEBATE; LACK OF INCENTIVE TO CRITICAL ATTITUDES, AMONG MANY OTHERS. THE REPLICATION OF THESE PROBLEMS, COMBINED WITH THE RECURRENT ABSENCE OF THE PROFESSOR RESPONSIBLE FOR THE COURSE, SEEMS TO US TO BE THE MAIN CAUSE OF THE WIDESPREAD PERCEPTION THAT SEMINARS ARE A METHOD OF LEARNING OF MINOR IMPORTANCE. OUR EXPERIENCE, HOWEVER, HAS SHOWN THAT THIS SCENARIO MAY CHANGE SIGNIFICANTLY IF DUE CARE IS EXERCISED.
\end{abstract}

\section{KEYWORDS}

LEGAL EDUCATION; METHODOLOGY; CONSTITUTIONAL RIGHTS; CASE LAW; SEMINARS. 
e consolidados no ensino do direito no Brasil: o respeito excessivo ao argumento de autoridade e a falta de uma cultura acadêmica que fomente a análise crítica e a livre discussão de ideias.

Foi o diagnóstico acerca desses vícios que levou à reflexão sobre alternativas didáticas que pudessem, se não eliminá-los, ao menos atenuá-los. Parecia claro que uma das principais formas (em alguns casos, a única forma) de ensino do direito no Brasil - a aula exclusivamente expositiva - contribuía fortemente para que tanto o respeito incondicional ao argumento de autoridade quanto a ausência de livre discussão de ideias continuassem a predominar entre nós. Parecia claro também que esse cenário era responsável por uma progressiva perda de motivação dos estudantes entre o início e a conclusão de seus cursos.

Diante da impossibilidade de uma alteração radical no processo pedagógico, visto que a disciplina em questão está inserida em uma grade curricular já estabelecida, com carga horária definida, ministrada em espaço físico não adaptado a outras possibilidades, com elevado número de alunos (na época, 120 por turma), ${ }^{1}$ a melhor saída pareceu ser um esforço no sentido de aperfeiçoar certo método de ensino que, embora utilizado há muito tempo nas faculdades de direito, costuma ser, em boa parte das vezes, mal aproveitado: os seminários. Este aproveitamento deficiente dos seminários deve-se sobretudo a uma deturpação muito comum no seu uso: em vez de ser um espaço propício ao debate entre os estudantes, os seminários constantemente reproduzem a racionalidade das aulas expositivas; a única diferença é a substituição da figura do professor-expositor pela do aluno-expositor. Isso com frequência leva à percepção de que os seminários são, na formação jurídica dos estudantes, menos importantes que as aulas dos docentes.

A premissa que adotamos foi a de que os seminários podem e devem se diferenciar das aulas expositivas, já que os alunos deixam de ser meros espectadores, com participação eventual e pontual, para tornarem-se protagonistas. No entanto, como ressaltado acima, tal protagonismo não pode ser baseado na exposição, mas tem de ser baseado no debate. Ou seja, o papel central que os estudantes devem ter nos seminários não deve decorrer da assunção da tarefa de expor a matéria a ser estudada, mas de uma participação maior e efetiva no debate. Nesse sentido, é preciso muito cuidado para que a parte de apresentação do seminário - ou seja, a exposição, por parte do estudante, do texto definido para aquela aula -, embora também importante, não ofusque o papel dos debates. Se a qualidade de uma aula expositiva depende, em grande parte, do conhecimento, da didática e das habilidades comunicativas do professor, os seminários dependem fundamentalmente da participação e da preparação dos alunos. Fomentar o aluno a participar deve ser, portanto, a própria razão de ser do seminário.

O que este artigo pretende mostrar é que as aulas de seminário, quando tomadas as devidas precauções, além de poderem ser interessantes e instigantes para os alunos, 
têm potencial para desenvolver conhecimentos, habilidades e atitudes que uma aula expositiva dificilmente conseguiria. Para tanto, escolhemos descrever como tem sido a experiência no uso desse método didático e pedagógico em uma situação concreta: os seminários realizados na disciplina direitos fundamentais, ministrada pelo professor Virgílio Afonso da Silva, na Faculdade de Direito da Universidade de São Paulo. ${ }^{2}$ Nossa proposta é compartilhar algumas experiências que consideramos positivas e submetê-las à crítica da comunidade acadêmica. Ou seja, não nos propomos, aqui, a fornecer alguma teoria abrangente, com pretensões universalistas, acerca do ensino jurídico ou a apontar de forma genérica alguns de seus problemas. Nossa intenção é mostrar como a "reformulação do já existente" pode contribuir para a melhora na formação do estudante de direito no Brasil.

Para atingir os objetivos propostos, este artigo está estruturado da seguinte maneira: na parte 1 será exposto aquilo que chamamos de "bastidores" dos seminários, ou seja, a forma como é feita a divisão das salas e dos grupos, a definição das duplas de estudantes, a escolha dos temas e do material de leitura, a seleção e a preparação dos monitores e o uso de sistemas eletrônicos de gestão de aprendizagem; a parte 2 é dedicada a apresentar a dinâmica dos seminários - apresentação dos textos e realização dos debates -; a parte 3 justifica a razão pela qual chegar a uma única "resposta correta" não é objetivo dos seminários; a parte 4 explica a forma de avaliação dos alunos; a parte 5 pretende mostrar o quão importante pode ser a presença do professor nos seminários; por fim, a parte 6 é dedicada a algumas reflexões finais.

\section{OS "BASTIDORES" DOS SEMINÁRIOS}

\section{I A DIVISÃo DAS SAlas}

No curso de graduação da Faculdade de Direito da Universidade de São Paulo havia, até 2007, duas turmas por período de estudo, ou seja, duas turmas no período matutino e duas no período noturno. Cada uma delas tinha por volta de 120 alunos. Em 2008, o número de turmas dobrou (quatro por período), e o tamanho de cada uma delas reduziu pela metade: sessenta alunos. Em ambos os casos - 120 ou 60 alunos - uma aula baseada em debates seria impossível. Por mais que nas aulas expositivas ${ }^{3}$ de direitos fundamentais haja uma provocação constante a que os estudantes participem, o nível de participação dificilmente poderá ser tão intenso. Por isso, tanto antigamente quanto hoje em dia, as turmas são divididas em grupos menores. ${ }^{4}$ Antes, esses grupos tinham por volta de 20 estudantes; hoje eles têm por volta de 16. Se a participação é um aspecto essencial de um seminário, as classes não podem ser grandes demais. Embora o conceito do que seja uma classe "grande" possa estar sujeito a discussão, neste texto ele significa uma sala com mais de vinte alunos. Existem algumas razões simples para fixar esse limite numérico. 
A primeira delas está associada ao tempo de aula. Imaginemos uma sala com cinquenta alunos, o que está muito longe de ser incomum, e que houvesse uma hora de aula. Isso significaria que, se todos os estudantes quisessem participar, cada um teria pouco mais de um minuto para se manifestar. ${ }^{5}$ Parece-nos claro que isso é pouco para que o aluno possa expor, com qualidade, seu ponto de vista sobre os diversos pontos abordados no seminário.

Uma segunda razão está associada à dinâmica pessoal. Turmas grandes tendem a amedrontar aquelas pessoas mais introvertidas, enquanto as turmas pequenas tendem a criar um ambiente mais íntimo, no âmbito do qual as pessoas podem se sentir mais à vontade para falar e, até mesmo, para discordar de colegas e monitores. Criam-se laços de empatia entre os alunos e entre alunos e monitores, o que, aos poucos, pode atenuar a timidez de alguns em falar para grandes públicos.

Por fim, uma última razão para a divisão das turmas em pequenos grupos está associada à avaliação. Se todos têm a oportunidade de participar do debate, torna-se possível também que essa participação seja avaliada. Em turmas pequenas, os monitores conhecem os alunos pelo nome e, como os alunos têm muitas oportunidades para participar, é possível perceber se o estudante leu ou não o material selecionado e, caso tenha lido, o quanto ele conseguiu aproveitar dessa leitura.

\section{I.2 A DefiniçÃo das duPlas de estudantes}

As apresentações dos textos são sempre feitas em duplas, com exceção dos casos em que a classe tenha número ímpar; nessa hipótese, o seminário que tiver maior carga de leitura é atribuído a um trio de estudantes. As duplas são formadas por ordem alfabética - às vezes de nome, às vezes de sobrenome -6 e não estão sujeitas à livre escolha dos alunos. O estabelecimento dessa regra tem duas razões, uma logística e outra ligada à dinâmica de trabalho: em primeiro lugar, deixar que a definição das duplas fique a cargo dos próprios estudantes exigiria um sistema de inscrições de duplas o qual poderia levar tempo para ser organizado e, sobretudo, para ser completado; a segunda razão, aqui denominada de "dinâmica de trabalho", diz respeito à relevância de o estudante aprender não apenas a trabalhar em equipe, mas também a interagir construtivamente com pessoas com as quais ele não necessariamente tem afinidade ou amizade. ${ }^{7}$

Os alunos, antes de apresentarem seus seminários, têm acesso a um roteiro simples, que explica o que se espera de um seminário, e com dicas sobre como apresentá-lo. ${ }^{8}$ Dessa forma, o aluno saberá de antemão como deverá formatar sua apresentação e quais os critérios com base nos quais será avaliado.

\section{I.3 A escolha dos temas}

É impossível abordar todos os temas relevantes no âmbito dos direitos fundamentais em apenas 10 ou 12 encontros ao longo do semestre. Isso também nunca nos pareceu 
necessário. Partimos do pressuposto de que o estudante não precisa discutir todas as normas constitucionais garantidoras de direitos fundamentais para ter uma sólida formação nessa disciplina. Para nós, aquele que aprende a pensar sobre os direitos fundamentais está apto a resolver qualquer problema que envolva esses direitos, mesmo que não tenha tido uma aula específica sobre determinada questão. ${ }^{9}$

A seleção dos temas (e textos) a serem discutidos ao longo do semestre tem, claro, um componente subjetivo e expressa, assim, as preferências daqueles que organizam o curso. Essa seleção, ainda que subjetiva, baseia-se em duas ideias básicas: (a) contemporaneidade do debate; e (b) possível aproveitamento da discussão para outros temas não abordados no semestre. A primeira ideia faz que sejam selecionados casos atuais, ${ }^{10}$ o que, além de despertar mais o interesse dos estudantes, exige que a lista de casos seja sempre renovada, evitando-se, dessa forma, o conhecido problema dos conteúdos programáticos que se engessam no tempo e são repetidos à exaustão por anos a fio (às vezes, por décadas). ${ }^{11} \mathrm{~A}$ segunda ideia indica que é melhor selecionar temas e casos cujo debate pode ser importante não apenas para aquela questão específica, mas também para outras correlatas.

\section{I.4 Seleção do material de leitura}

Para os seminários, os alunos leem principalmente decisões judiciais, quase que exclusivamente acórdãos do Supremo Tribunal Federal. Sempre que possível, são escolhidos acórdãos em que haja voto vencido, para que os alunos tenham acesso a um número maior de argumentos e teses divergentes. Como alternativa, pode-se optar pela leitura da petição inicial e pelo voto de um ministro que tenha decidido de forma contrária àquela sustentada na petição, ${ }^{12}$ ou ainda pela leitura de um amicus curiae e um voto o qual sustente tese contrária. Para certos temas, quando há algum caso importante e atual, no qual ainda não há decisão, pode-se optar também por utilizar apenas a petição inicial e uma manifestação em sentido contrário (parecer da Advocacia-Geral da União, de procuradorias e amici curiae, por exemplo). Em todos os casos, os estudantes acabam por incorporar o papel de ministros do Supremo Tribunal Federal.

A escolha por trabalhar preferencialmente com jurisprudência deveu-se, em primeiro lugar, à percepção de que o estudo das decisões judiciais não tem sido proporcional à importância cada vez maior que o Judiciário - o Supremo Tribunal Federal, em especial - tem tido na vida jurídica, social, econômica e política do país. Durante o curso de direito, os estudantes não costumam ter muitas oportunidades de ler decisões judiciais e - o que nos parece ainda mais grave - não são treinados para analisá-las criticamente.

Uma segunda razão para o foco na jurisprudência está intimamente associada ao nosso objeto de estudo: os direitos fundamentais. Nosso ponto de partida foi o seguinte: não é possível compreender os limites e as possibilidades de exercício de 
cada direito fundamental se não analisarmos as colisões que cada forma de exercício desses direitos pode gerar. No Brasil, o ensino dos direitos fundamentais ainda parece pressupor a possibilidade de apreender a priori os limites de cada um dos direitos fundamentais em espécie. Se aceitássemos essa possibilidade, talvez fosse possível supor que o ensino baseado na doutrina pudesse ser suficiente. Como nosso ponto de partida era diverso, porque rejeitamos essa possibilidade de definição de limites $a$ priori e em abstrato dos direitos fundamentais, nunca nos pareceu possível imaginar uma aula que fosse baseada na concepção abstrata de cada um desses direitos. ${ }^{13}$ Daí a opção, desde o primeiro momento, por um enfoque concreto, baseado em casos reais, em que dois ou mais direitos fundamentais se encontrassem em uma situação de colisão.

A terceira razão para debater casos concretos diz respeito à tentativa de se romper com um certo distanciamento entre teoria e prática, infelizmente frequente no ensino jurídico. Não é o caso de reviver aqui o estéril debate acerca da prevalência da teoria sobre a prática ou da prática sobre a teoria. Esse debate apenas aprofunda o distanciamento entre ambas. Nosso ponto de vista a esse respeito sempre foi relativamente simples e direto: se se espera que os estudantes de direito aprendam e dominem um arsenal teórico que lhes possibilite argumentar e resolver problemas reais, parece-nos plausível supor que tal arsenal pode e deve ser testado com casos reais. Isso significa que o estudante precisa demonstrar não apenas que compreendeu corretamente o funcionamento desse instrumental em tese, mas também que é capaz de operá-lo e aplicá-lo.

Um exemplo frequente em nossos seminários pode ilustrar isso com mais clareza. Nas aulas teóricas, o aluno toma contato com a máxima da proporcionalidade como forma de controle de atos estatais os quais restringem direitos fundamentais. Ele aprende que essa máxima é formada por três testes: a adequação, a necessidade e a proporcionalidade em sentido estrito. ${ }^{14}$ Sempre nos pareceu fundamental que os estudantes, além de decorarem o que esses três testes significam, deveriam estar aptos a aplicá-los, para analisar um caso concreto e para avaliar se a aplicação que o Supremo Tribunal Federal fez da proporcionalidade em determinado caso real é consistente com os pressupostos teóricos estudados (ou com algum pressuposto teórico alternativo). Assim, os estudantes terão também a oportunidade de refletir criticamente sobre a teoria, ao ver como é a sua aplicação na solução de problemas reais.

\section{I.5 SEleção dos MONitores}

Uma vez que o êxito das aulas de seminário depende, em certa medida, de determinadas capacidades e aptidões dos monitores que coordenam os debates, o processo de seleção destes tem então uma relevância inegável. Inicialmente, cogitou-se fazer um processo seletivo formal. No entanto, um procedimento como tal acabaria sendo necessariamente centrado em uma única prova (oral ou escrita), já que, ao contrário 
do que ocorre com processos seletivos ou concursos docentes, a análise de currículo não seria capaz de fornecer grandes subsídios, visto que os candidatos seriam todos ainda estudantes. Por isso, e por entendermos que uma única prova poderia, quando muito, revelar conhecimentos dos candidatos sobre o conteúdo da disciplina, mas não o seu enquadramento no perfil desejado para a função, a ideia de um processo seletivo nesses moldes foi descartada.

Se o que se quer é encontrar pessoas com determinado perfil, ${ }^{15}$ e não apenas com determinados conhecimentos, entendemos que a melhor forma de alcançar esse objetivo seria por meio de uma avaliação continuada, e não momentânea. Os monitores são então selecionados de duas formas distintas. O primeiro grupo de monitores é formado pelos orientandos de mestrado e doutorado do responsável pela disciplina, professor Virgílio Afonso da Silva. Por trabalhar de forma intensa com o próprio professor responsável, esses estudantes têm um contato mais direto e constante com a forma de trabalho esperada em um curso que se pretende focado no livre debate de ideias. O segundo grupo de monitores é selecionado entre os alunos dos cursos de pós-graduação ministrados pelo docente. Como esses cursos também são focados no debate, o professor tem um semestre inteiro para observar os estudantes os quais parecem mais se adequar ao perfil esperado. ${ }^{16}$

\section{I.6 PreparaçÃo dos monitores}

Há dois momentos importantes na preparação dos monitores. O primeiro deles é no início do semestre, antes do início do curso. O segundo são as reuniões que ocorrem antes de cada seminário.

Como os seminários estão baseados em premissas e diretrizes cuja implementação é imprescindível para o seu êxito, é importante que elas fiquem claras, desde o início, para todos os participantes. Por isso, ainda antes do início das aulas é realizada uma reunião, para que os novos monitores sejam esclarecidos acerca da dinâmica dos seminários, da seleção dos textos, dos critérios de avaliação etc. É importante que os monitores saibam, a princípio, o que deles se espera e que o bom desempenho de suas tarefas é fundamental para o bom andamento do curso.

Além disso, antes de cada seminário há uma reunião entre o professor e os monitores. Essas reuniões não servem para que o professor simplesmente oriente os monitores. A ideia é semelhante àquela na qual os seminários estão baseados: monitores e professor debatem livremente, procurando estabelecer quais são os pontos mais interessantes a serem discutidos naquele caso específico. As reuniões costumam durar entre 60 e 90 minutos (nos casos de reuniões para discutir dois temas, a duração pode ser de 120 minutos). Após a reunião, o professor elabora um roteiro que reproduz, com detalhes, os principais pontos discutidos. Esses serão, basicamente, os pontos os quais os monitores deverão explorar com os estudantes nos seminários e que, portanto, pautarão o debate. ${ }^{17}$ 
A reunião é fundamental na preparação dos monitores e tem reflexos na qualidade do seminário. Discutir o tema anteriormente ao seminário dá uma maior segurança ao monitor, pois ele já conhecerá os principais caminhos que a discussão pode percorrer, saberá os argumentos e as informações mais importantes sobre o tema, terá um entendimento mais consolidado e refinado sobre o caso e encontrará um espaço para tirar suas dúvidas e testar suas ideias antes de entrar em sala de aula. Desde o início, nunca nos pareceu plausível simplesmente atribuir temas e textos aos estudantes e "jogar" os monitores para a condução dos debates, sem um debate prévio entre monitores e professor.

A reunião tem também a função de informar os monitores sobre o que os alunos têm aprendido nas aulas expositivas do docente. Isso permite um alinhamento entre aquilo que se ensina nas aulas expositivas e aquilo que se discute nos seminários, o que tem dois efeitos positivos: evita que o monitor avance mais do que deveria no debate (já que é possível que alguns temas ainda sejam objeto de aula expositiva posterior); e evita que se perca tempo explicando o que todos já sabem ou deveriam saber. Dessa forma, o curso ganha maior coesão e dinamismo.

Os roteiros de seminários, aos quais os alunos não têm acesso, também cumprem a função de impedir que pontos importantes de cada caso deixem de ser discutidos ou que o debate seja dominado por questões de menor importância ou que fujam do escopo de um curso de direitos fundamentais. É preciso deixar claro, contudo, que os monitores têm liberdade para conduzir os debates conforme o ritmo de cada grupo. O roteiro garante uma uniformidade de informações e pontos de debate em todos os grupos, mas cada um seguirá seu ritmo, de acordo com a capacidade dos alunos de desenvolver e apreender os argumentos em discussão. ${ }^{18}$

\section{I.7 A COOPERAÇÃo NA CONDUÇÃo dos DEBATES}

Não são apenas os estudantes que têm que trabalhar em dupla (quando da apresentação do seminário), mas também os monitores. Desde o início, optamos explicitamente por dois monitores por grupo de seminário. Esse trabalho em dupla tem, a nosso ver, inúmeras vantagens. A primeira delas é o fomento ao diálogo não apenas entre os alunos, mas também entre os monitores. Além disso, em muitas situações um monitor acaba "controlando" o outro, às vezes fazendo até mesmo um papel de opositor. Nesses casos, o papel de "advogado do diabo" que muitas vezes cabe aos monitores em relação aos alunos passa a ser exercido também por um monitor em relação ao outro. Dessa forma, o fomento ao dissenso deixa de ser apenas um lema que os monitores procuram inculcar nas atitudes dos estudantes e passa a ser exercitado também por aqueles que conduzem o debate. Essa não necessária concordância total entre monitores reforça, ainda, um dos pressupostos dos seminários, que é a inexistência de uma única resposta correta para todo e qualquer problema discutido. ${ }^{19}$ Como os monitores não são professores de carreira, o trabalho em dupla tem ainda o benefício do apoio mútuo 
e da solidariedade entre eles, o que tende a aumentar a sua confiança e diminuir o seu natural nervosismo. Por fim, no que diz respeito à avaliação dos alunos, a presença de dois monitores tende a promover maior equilíbrio na atribuição de notas.

$\mathrm{Na}$ definição das duplas de monitores, há um importante critério, que pode ser resumido pela ideia de heterogeneidade. Assim, se entre os monitores há alunos tanto de graduação quanto de pós-graduação, é importante que não exista uma dupla formada apenas por alunos de graduação. Ademais, se há monitores que já participaram das monitorias nos semestres anteriores e monitores novos, também é recomendável que as duplas reflitam essa situação.

\section{I.8 O USO DE SISTEMAS ELETRÔNICOS DE GESTÃO DE APRENDIZAGEM}

Embora o curso de direito ainda possa ser realizado sem a necessidade de recursos tecnológicos, desde o início pareceu-nos importante aproveitar as vantagens que a tecnologia poderia oferecer. A Universidade de São Paulo oferece a todos os seus docentes acesso a um sistema de gestão de aprendizagem - Learning Management System (LMS) - chamado Moodle. ${ }^{20}$ Em breves palavras, esse sistema consiste em um ambiente virtual acessível pela internet no qual são disponibilizadas as informações mais relevantes concernentes ao curso: calendário, horário e temas das aulas (expositivas e de seminário), divisão das salas e dos grupos de apresentação. Além disso, o Moodle permite aos alunos entrar em contato com o professor e com os monitores (e ao professor e aos monitores, entrar em contato com os alunos) e permite ao professor publicar as notas e divulgar palestras e outros eventos extraclasse de interesse para o curso.

Todo o material de leitura para seminário (e parte do material das aulas expositivas) está disponível em formato eletrônico no Moodle. Essa forma de disponibilizar o material de leitura é mais fácil, cômoda, econômica e ecologicamente correta.

\section{A DINÂMICA DOS SEMINÁRIOS}

\section{I A Apresentação dos textos}

O seminário é dividido em duas partes principais. Ele inicia com a exposição do caso pela dupla previamente definida, e, após a apresentação, passa-se diretamente ao debate que envolve todos os estudantes do grupo. Como já foi exposto anteriormente, um princípio fundamental de nossos seminários é o de que o foco deve ser sempre o debate. Assim, a exposição dos casos selecionados é apenas a base para esse debate. Portanto, é indispensável não permitir que a exposição se prolongue além do tempo previamente definido. ${ }^{21}$

Em um primeiro momento, alguns estudantes têm dificuldade em dosar o tempo de sua apresentação e, mais do que isso, não compreendem a rigidez no controle que 
os monitores fazem desse tempo. Nossa premissa é a de que o limite de tempo é necessário, por diversas razões: em primeiro lugar, e mais importante, para que sobre o devido tempo para o debate; em segundo lugar, porque promove certa objetividade nas apresentações, já que não há tempo para devaneios ou digressões irrelevantes; e, por fim, porque serve como treino para os estudantes, que, ao longo de sua vida profissional, serão confrontados com várias situações semelhantes, isto é, situações nas quais o tempo de uso da palavra é limitado. Além disso, a limitação do tempo de apresentação é decorrência de outra premissa na qual o funcionamento de nossos seminários se baseia: a de que todos os alunos (e não só os expositores) leram todos os textos. Se isso é verdade, não deve ser tarefa dos expositores relatar integralmente o que leram (seria redundante), mas sim sistematizar e analisar criticamente o material que estudaram com mais tempo e atenção do que os outros. Como já foi dito, isso os força a avaliar o que é central nos argumentos e o que é secundário. Esse é um treino de leitura importantíssimo, que também contribuirá de forma relevante na formação dos estudantes.

Por fim, além desse desenvolvimento na habilidade de selecionar as informações mais relevantes para a apresentação, o aluno pratica sua comunicação oral. O objetivo é fazer que os estudantes desenvolvam habilidades como: organizar suas ideias de modo que sua exposição não fique confusa; lidar com o nervosismo de falar em público e ser avaliado; interagir com a plateia, se necessário; e treinar dicção e empostação da voz. Essas são habilidades as quais serão muito úteis para o futuro dos estudantes, independente de que carreira queiram seguir.

\subsection{Debates}

O debate, como já foi várias vezes salientado, é o cerne das aulas de seminário. É nesse momento que os monitores têm um papel mais relevante a cumprir. Sua função não é dar uma aula sobre o tema ou convencer os alunos a adotar determinado ponto de vista. Os monitores devem ter a função de provocadores, e não de doutrinadores, no sentido usualmente adotado no ambiente jurídico. Monitores que expressam posicionamentos muito definitivos sobre certo tema podem ou criar um indesejável consenso e acabar com o debate - o que poderia reproduzir, no seminário, o vício do argumento de autoridade - ou criar uma polarização maniqueísta capaz de transformar o debate em polêmica estéril.

De maneira a evitar esses dois cenários indesejáveis, os monitores devem incentivar os alunos a pensar criticamente, começando por identificar possíveis incoerências, inconsistências, contradições e pontos obscuros nos votos dos ministros do STF (ou nas petições iniciais, nas manifestações de procuradorias ou a Advocacia-Geral da União, ou, ainda, em amici curiae). Além de fomentar uma análise crítica por parte do aluno, isso pode ser uma poderosa arma para desconstruir o argumento de autoridade. ${ }^{22}$ Ao monitor cabe esse papel de iniciar questionamentos que incitem essa visão 
crítica, e, como demonstrou a experiência, os alunos logo adquirem conhecimento e confiança para fazer o mesmo por conta própria. É ao mesmo tempo interessante e gratificante notar como, à medida que progride o semestre, os próprios alunos tornam-se capazes de reflexões críticas refinadas e bem fundamentadas sobre os textos lidos nos seminários. Seguramente, a habilidade de analisar criticamente um texto acadêmico ou uma decisão, independente de quem seja o seu autor, é algo que acompanhará o aluno pelo resto de seu curso e em sua vida profissional.

Espera-se, portanto, que o aluno perceba que o seu aprendizado está diretamente relacionado com a sua capacidade de fazer perguntas, tanto em termos qualitativos (perguntas apropriadas) quanto em termos quantitativos (perguntas que procurem cobrir a maior parte das questões envolvidas no debate). O desempenho dos alunos durante o seminário é diretamente proporcional à sua preparação prévia, e, nessa preparação, cabe a ele fazer a si mesmo as perguntas apropriadas. Em última análise, o aprendizado por meio do livre debate de ideias é um aprendizado por meio de perguntas, porque são elas que indicarão os caminhos para as respostas. Assim, o papel dos monitores é atuar também como facilitadores ou mediadores desse processo, indicando as perguntas apenas quando os próprios alunos não as façam.

Algo que pode diminuir o rendimento de um seminário - e ao qual o monitor deve estar sempre atento - são os momentos em que a discussão corre o risco de cair no lugar-comum. Esse é um risco particularmente grande quando a discussão tem como objeto os direitos fundamentais, já que eles frequentemente estão cercados de polêmicas as quais permeiam não apenas a literatura jurídica, mas também o grande público e a imprensa. Isso significa que, muitas vezes, os alunos já vêm com uma posição pré-definida e, não raro, irrefletida sobre aquilo que será discutido.

Portanto, é imprescindível exigir que toda manifestação no debate seja devidamente fundamentada e faça referência ao material de leitura. Isso força os estudantes a irem além de suas pré-compreensões, muitas vezes baseadas em argumentos não jurídicos. A despeito da importância desses argumentos, é necessário que os estudantes se acostumem a uma exigência de fundamentação legal e jurídica, que, existindo, aí sim pode ser complementada por argumentos de outra ordem.

O monitor deve também impedir que se chegue muito facilmente a consensos em torno de determinados pontos do debate. Se a sala pende a adotar determinada posição, cabe ao monitor mostrar os argumentos do lado oposto. Isso é fundamental para que os alunos tenham consciência da complexidade das questões e os obriga a refinar ainda mais suas opiniões e análises sobre o tema. Mais importante do que chegar a uma única resposta final para o debate - o que normalmente não é alcançado -23 é ser treinado e incentivado a apresentar argumentos consistentes sobre todo e qualquer ponto de vista essencial para o debate.

Por fim, o monitor, além de provocador, tem um papel fundamental na dinâmica da discussão: impedir que alguns poucos estudantes monopolizem o uso da palavra 
e incentivar a participação de todos. Também deve fazer os alunos entenderem que discordar e debater é parte fundamental do aprendizado e um exercício de crescimento mútuo. Para isso, é importante que o monitor dê o exemplo. Se ele está aberto a ouvir críticas, a ser provocado pelos alunos e a aprender com eles, é bem provável que esse comportamento seja repetido por toda a sala.

\subsection{UMA ATIVIDADE COMPLEMENTAR: A SIMULAÇÃO}

Nos últimos anos, quando a carga horária assim permitia, foi realizada também uma atividade complementar aos seminários, a qual chamamos de simulação. Tal simulação consiste na atribuição de alguns papéis que serão desempenhados pelos estudantes, como ministros do STF, advogados da União, algum legitimado para propor ADI, associações que atuem como amici curiae, entre outros. Essa atividade é sempre a última do semestre, porque deve se beneficiar do aprendizado ao longo do curso e dos debates de seminário. A ideia central da atividade é migrar dos debates, os quais são sempre realizados a partir da perspectiva do observador, para a ação concreta, ainda que simulada, a partir da perspectiva do participante. Definido o tema - que pode ser um tema já discutido em aula anterior -, cada ator deve assumir o seu papel e agir de acordo com ele. Isso faz que os alunos deem ainda mais importância para uma argumentação bem construída. Quando se colocam na posição de partes e de ministros, eles conseguem perceber que são capazes de produzir bons argumentos. É perceptível a satisfação com a descoberta das várias possibilidades de aplicação daquilo que aprenderam ao longo do semestre.

Para deixar esse exercício ainda mais interessante, e para evitar que a defesa cega de uma posição pré-definida possa comprometer a qualidade dos argumentos, procuramos, na medida do possível, atribuir aos alunos papéis que não refletem a sua convicção pessoal. Em um dos semestres, o objeto da simulação foi o controle da constitucionalidade de uma determinada política de ação afirmativa. Como esse caso já havia sido debatido no início do semestre, os monitores tinham como tarefa observar, entre os alunos, quem defendia qual posição. No exercício de simulação, no fim do semestre, aqueles que, no debate em seminário, haviam defendido com mais entusiasmo a constitucionalidade da política de ação afirmativa eram escalados para propor uma ADI arguindo sua inconstitucionalidade; já aqueles que eram contra esse tipo de política eram escalados para defendê-la. Isso solidificava ainda mais um dos objetivos centrais da disciplina, a construção de argumentos consistentes.

\section{A IneXistênCIA de uMa Única resposta CORRETA}

Em geral, o ensino jurídico está baseado na premissa de que o professor tem como função fornecer aos alunos a resposta correta aos problemas e questões mais importantes de sua disciplina. Mesmo nos casos em que existe espaço para o debate, 
dificilmente esse objetivo é abandonado. É perceptível como os alunos se acostumam com essa postura. Para eles, é reconfortante ter acesso àquilo que alguém supostamente mais experiente considera como a melhor resposta aos problemas estudados.

Nossos debates tentam evitar ao máximo essa postura. Para usar como exemplo alguns dos vários casos discutidos ao longo dos últimos anos, partimos do pressuposto de que não faz grande sentido dizer aos alunos se o aborto, as ações afirmativas, a quebra de sigilo bancário, as restrições ao direito de reunião ou a obrigatoriedade de diploma de jornalismo são constitucionais ou inconstitucionais. Nossos debates baseiam-se na premissa de que é o próprio estudante - após várias rodadas de argumentos - quem deve decidir qual resposta é mais sólida. Essa decisão, como dito anteriormente, dependerá do desenvolvimento de um raciocínio coerente e condizente com normas do ordenamento jurídico e com as regras específicas de cada tema. O que interessa é a capacidade do aluno de justificar a escolha da resposta que considera correta, e não simplesmente a escolha em si.

É importante salientar que essa premissa - a inexistência de uma única resposta correta - não é apenas uma premissa didática, ou seja, uma construção artificial com o intuito apenas de abrir espaço para que os alunos possam debater. Essa é uma premissa teórica do curso. O curso não compartilha do chamado "otimismo metodológico" (SILVA, 2005, p. 143), o qual supõe que basta a escolha do método "correto" de interpretação constitucional para se alcançar uma resposta certa, que estaria à espera de ser descoberta. Respostas certas, para as finalidades do curso, são as respostas bem fundamentadas, com argumentos bem construídos e coerentes. Com isso se quer dizer que a inexistência de uma única resposta correta vale tanto para os alunos quanto para os ministros do STF. Além de outras consequências, isso desmistifica sensivelmente o processo de interpretação constitucional. A todo tempo, decisões são tomadas entre várias opções, o que fica visível já a partir do material de leitura, que fornece no mínimo duas respostas em tese igualmente plausíveis para um mesmo problema. Quando os alunos se dão conta dessa pluralidade de opções, percebem também a dinâmica que está por trás da atuação dos ministros, da Advocacia-Geral da União, das procuradorias e dos amici curiae. Percebem também que eles mesmos podem ser atores neste processo de interpretação constitucional.

\section{Avaliação dos alunos}

Os estudantes são avaliados em dois quesitos: apresentação do seminário e participação nos debates. Nos seminários, avalia-se o quanto o aluno se preparou para sua apresentação, se leu com atenção o texto, se procurou entender bem o problema, se soube identificar os argumentos mais relevantes, se conseguiu refletir criticamente sobre o conteúdo da apresentação e se a apresentação foi clara e didática. As notas são atribuídas individualmente a cada membro da dupla ou do trio que apresenta. 
Essa é uma forma de atenuar o "efeito carona" que muitas vezes ocorre em trabalhos em grupo, quando uns se aproveitam do esforço e do trabalho dos outros para obter a mesma nota.

Já a nota de participação pretende refletir a quantidade e a qualidade das intervenções nos debates. Avaliar quantidade não significa, aqui, que, quanto mais intervenções, maior será a nota. Muitas vezes o excesso de participação, como o quase monopólio do uso da palavra, com intervenções muito longas e com pouca fundamentação, pode ser tão prejudicial à discussão e, consequentemente, à avaliação, quanto a não participação. Assim, quando falamos em avaliar a quantidade, queremos fazer menção à quantidade dentro dos limites do razoável e, sobretudo, com qualidade.

Um dos pontos que merecem especial atenção no momento de avaliar a qualidade das intervenções é a percepção acerca da leitura do material. Como já foi dito, os alunos são os protagonistas dos seminários, e a boa participação depende dessa leitura. Se isso não ocorre, a discussão não progride ou fica em um nível muito baixo. É tarefa do monitor perceber quando a participação do estudante é simplesmente baseada na reprodução, eventualmente com outros termos, daquilo que ele acaba de ouvir no debate. Muitos estudantes são extremamente comunicativos e têm a capacidade de intervir no debate mesmo sem preparação prévia. Essa capacidade, ainda que possa ter seu lado positivo, não pode ser levada em consideração na avaliação da qualidade da participação.

A atribuição da nota de participação, embora seja a que menor peso tem na nota final do aluno, é aquela que em geral suscita mais polêmica entre os estudantes. Isso porque muitos dos estudantes que participam bastante podem ficar frustrados com uma nota que não lhes pareça compatível com a quantidade de intervenções ao longo do semestre. É comum que o estudante não perceba qual foi a sua real contribuição para os debates. Após alguns anos de experiência, e com o intuito de evitar essa situação de frustração, passamos a divulgar, no meio do semestre, uma "nota provisória de participação”. Essa nota, que não será utilizada para nenhum cálculo de média final, tem como objetivo indicar ao aluno como tem sido a sua participação no debate. Para alcançar tal objetivo, ela é acompanhada de uma fundamentação. Em outras palavras, essa nota tem como função transmitir ao aluno a seguinte mensagem: "se o semestre terminasse hoje, sua nota de participação seria $x$, pelas razões $a, b$ e $c$ ". Isso permite que o aluno o qual receba uma nota provisória baixa tenha tempo ainda para modificar sua postura nos debates e, ao final do semestre, obter uma avaliação melhor (e isso geralmente é o que acontece); ademais, permite àqueles que recebem uma nota provisória alta saber que seu desempenho está dentro das expectativas do curso.

Além da introdução da chamada "nota provisória", atribuída no meio do semestre, ao longo dos últimos anos fizemos algumas modificações na forma como a nota de participação é atribuída. No início, ela era uma nota como as outras, ou seja, seguia 
a escala de 0,0 a 10,0. Depois de alguns semestres, percebemos que essa escala gerava dificuldades de atribuição por parte dos monitores e de compreensão por parte dos alunos, já que nem sempre é possível explicar, por exemplo, o que diferencia um aluno nota 7,5 de um aluno nota 8,0. Uma segunda tentativa foi transformar a nota de participação em um ponto de participação. Como a nota era responsável por 10\% da média final, decidimos transformá-la em um ponto nessa média. Ao mesmo tempo, diminuímos o número de degraus na escala, passando a haver apenas três possibilidades de atribuição: 0,$0 ; 0,5 ; 1,0$. Embora isso tenha solucionado vários problemas de atribuição e compreensão, após alguns semestres chegamos à conclusão de que apenas três níveis eram insuficientes para expressar as diferenças entre os alunos. Por fim - e esse é o nosso modelo atual -, decidimos manter o sistema de um ponto na média final, mas com mais degraus: 0,$0 ; 0,25 ; 0,5 ; 0,75 ; 1,0$. Além disso, para que haja uma certa uniformidade de critérios entre os grupos, fizemos uma tabela com os principais perfis de participação ${ }^{24}$ e as formas como eles se encaixam nesses cinco valores possíveis de notas de participação.

\section{A PRESENÇA DO PROFESSOR}

Já foi dito acima que não são poucos os estudantes que veem nos seminários uma atividade menos importante porque normalmente é realizada sem a presença do professor (alguns pensam até mesmo que essa é uma fórmula que o professor utiliza para se livrar de parte de suas tarefas didáticas).

Para que essa percepção seja combatida, sempre foi premissa de nossos seminários que a presença do professor é fundamental. Mas, como a classe é dividida em pequenos grupos, os quais se reúnem em salas distintas, não é possível que o professor participe de todos os debates. Nunca nos pareceu produtivo também que ele ficasse alguns poucos minutos em cada um dos grupos, pois isso poderia atrapalhar o debate.

Por isso, desde o início, a decisão foi no sentido de que a cada semana o professor deveria participar do debate em um grupo diferente, mas participar do debate do começo ao fim, junto com os estudantes e com os monitores. ${ }^{25}$ Estar presente e participar dos debates, ainda que apenas em um grupo a cada vez, tem o potencial de aumentar o respeito e a consideração que os estudantes têm pela atividade a qual estão desenvolvendo e combate o preconceito de considerar o seminário uma atividade menos importante. E, na medida em que o professor, ao participar do debate, não desempenha o papel de "portador da resposta correta, da opinião da cátedra", mas apenas a função de um provocador extra, ao lado dos monitores, a ideia de horizontalidade entre os participantes é mantida, e a presença do docente não desvirtua, portanto, a natureza e os objetivos dos seminários. Pelo contrário, alguns alunos se sentem ainda mais estimulados a participar, por ter a oportunidade de debater com o professor em um ambiente distinto do ambiente tradicional da aula expositiva. 


\section{REFLEXÕES FINAIS}

De maneira geral, o objetivo deste artigo foi demonstrar que nem sempre são necessárias reformulações radicais na metodologia do ensino jurídico para que resultados positivos sejam alcançados. ${ }^{26}$ Algumas das formas tradicionais de ensino - no caso em questão, os seminários - às vezes não produzem os efeitos desejados por deficiências no planejamento ou por reproduzirem alguns vícios do ensino jurídico, como: (a) ensino não participativo; (b) foco no argumento de autoridade; (c) muita exposição e pouco debate; (d) falta de incentivo a posturas críticas, entre outros. A reprodução desses vícios, aliada ao fato de que, nos seminários, muitas vezes o professor está ausente, parece-nos ser a causa da percepção generalizada de que aulas de seminários são uma forma menos importante de aprendizado.

Nossa experiência nos últimos seis anos tem demonstrado que esse cenário pode ser muito diferente. O gosto dos alunos pelo debate, pela liberdade argumentativa, aumenta perceptivelmente a cada nova reunião. Ao fim de um semestre, a pergunta que dá título a este artigo simplesmente deixa de fazer sentido. O livre debate de ideias faz com que fique claro aos estudantes que muito melhor do que o argumento de autoridade é a autoridade do argumento.

: ARTIGO APROVADO (08/05/2010) : RECEBIDO EM 11/10/2009 


\section{ANEXO I}

\section{INSTRUÇÕES SOBRE OS SEMINÁRIOS}

As instruções abaixo são explicadas aos alunos no primeiro dia de aula e ficam disponíveis no Moodle durante todo o semestre. Elas têm como objetivo guiar os estudantes na preparação e na apresentação de seus seminários.

\section{A. O QUe SE espera dos alunos na APRESEntaÇão dos SEminários?}

Cabe à própria dupla de alunos que apresentará o seminário definir o que cada um dos integrantes vai expor. O número de textos e de páginas para cada seminário pode variar sensivelmente. Assim, nem sempre será simplesmente possível dividir tarefas com base no lema "cada aluno apresenta um texto". O diálogo entre os apresentadores é, portanto, fundamental. Isso é ainda mais importante quando, nos casos das decisões judiciais, há votos de vários ministros. Não é possível que, sem ler a decisão por completo, os alunos dividam quem vai expor que voto, a partir do simples critério "eu faço os quatro primeiros, você faz os últimos". Uma divisão feita dessa forma poderá significar idas e vindas na argumentação que podem ter como consequência uma exposição pouco sistemática (com uma nota correspondentemente baixa).

\section{B. Nos casos de decisões (ou votos de ministros, petições iniciais ou Amici} CURIAE), ESPERA-SE QUE O ALUNO EXPONHA:

1. O caso concreto que deu ensejo à ação (pode ser, de fato, um caso concreto ou uma lei impugnada via ADI).

2. Qual é o teor da decisão (ou do voto do ministro, quando for um voto isolado).

3. Quais são os dispositivos constitucionais e legais que fundamentaram a decisão.

4. Quais são os argumentos que embasaram a decisão (ou o voto do ministro).

5. Avaliação crítica dos argumentos.

(Obs.: detalhes meramente processuais dos casos não precisam ser levados em consideração)

\section{Alguns conselhos:}

1. O tempo de apresentação é limitado (total: 20 minutos). Tenha sempre um relógio à mão e treine em casa para ver se o tempo é suficiente (é normal que pensemos que será tudo muito rápido e não percebamos o tempo passar).

2. Prepare a exposição, faça anotações.

3. Concentre-se no fundamental e deixe o acessório de lado. Esse é a verdadeiro desafio na apresentação de um texto.

4. Leia tudo com espírito crítico e deixe de lado o argumento de autoridade. Uma de suas tarefas é perceber possíveis inconsistências nos argumentos dos ministros. 
112

QUEM SOU EU PARA DISCORDAR DE UM MINISTRO DO STF?

5. Não leve um texto de apoio, mas apenas anotações de pontos importantes.

Muita informação pode confundir na hora da exposição. Em outras palavras: em geral, é contraproducente levar o texto da decisão com suas anotações pessoais e passar página por página para expor essas anotações.

6. Não fique nervoso e encare tudo como um treino para a vida profissional. É um treino sujeito a avaliação e nota, mas é um treino. 


\section{AneXo 2}

\section{LISTA DE MONITORES (2004-2009)}

2004

Cristina Emy Yokaichiya

Felipe de Paula

José Francisco Rosetto

Leandro Varison Costa

Natasha Schmidt Caccia

Rafael Francisco Alves

Regis Anderson Dudena

Rosimeyre Marçal

Thomaz Henrique Junqueira de Andrade Pereira

\section{5}

Cristina Emy Yokaichiya

Evorah Lusci Costa Cardoso

Fabricio Antonio Cardim de Almeida

Felipe de Paula

Fernanda Vargas Terrazas

Joana Zylbersztajn

Leandro Varison Costa

Marina Nunes Rodrigues de Menezes

Paulo Macedo Garcia Neto

Rosimeyre Marçal

Thomaz Henrique Junqueira de Andrade Pereira

2006

Adriana de Moraes Vojvodic

Bianca Galafassi

Bruno Ramos Pereira

Claudio Mendonça Braga

Daniel Wei Liang Wang

Evorah Lusci Costa Cardoso

Fabricio Antonio Cardim de Almeida

Fernanda Vargas Terrazas

Laura Maniero

Marina Nunes Rodrigues de Menezes

Thaís Coimbra Marigo 


\section{7}

Adriana de Moraes Vojvodic

Ana Carolina Alfinito Vieira

Daniel Wei Liang Wang

Dennys Marcelo Antonialli

Gustavo Dantas Ferraz

Manuela Oliveira Camargo

Mariana Mazzini Marcondes

Paula Fernanda Alves da Cunha Gorzoni

Priscila Maddalozzo Pivatto

Rafael Silza Izaias

Stephanie Yukie Hayakawa da Costa

Tatiana Robles Seferjan

\section{8}

Ana Carolina Alfinito Vieira

Ariella Toyama Shiraki

Daniel Gustavo Falcão Pimentel dos Reis

Daniel Wei Liang Wang

Dennys Marcelo Antonialli

Flavio Beicker Barbosa de Oliveira

Léo Ferreira Leoncy

Paula Fernanda Alves da Cunha Gorzoni

Rafael Scavone Bellem de Lima

Sérgio Fiuza de Mello Mendes Filho

\section{9}

Adriana de Moraes Vojvodic

Bruno Ramos Pereira

Claudio Mendonça Braga

Daniel Gustavo Falcão Pimentel dos Reis

Daniel Wei Liang Wang

Fabricio Antonio Cardim de Almeida

Joana Zylbersztajn

Paula Fernanda Alves da Cunha Gorzoni

Rafael Scavone Bellem de Lima 


\section{NOTAS}

* Como será visto adiante, este texto é o relato de uma experiência concreta, construída e aperfeiçoada ao longo dos últimos 6 anos. Assim, talvez fosse mais preciso indicar como autores todos aqueles que participaram dessa empreitada, desde o seu início até o presente momento. Diante da impossibilidade de se fazer isso, gostaríamos ao menos de agradecer a todos os monitores e monitoras que trabalharam nesse projeto, cujos nomes estão listados no anexo 2. É imprescindível, contudo, fazer um agradecimento específico a Adriana de Moraes Vojvodic, Regis Anderson Dudena, Felipe de Paula, Paula Fernanda Alves da Cunha Gorzoni, Evorah Lusci Costa Cardoso, Paulo Macedo Garcia Neto, Priscila Pivatto, Fernanda Vargas Terrazas, Rafael Alves, Fabricio Antonio Cardim de Almeida e Rafael Scavone Bellem de Lima, em razão da atenta leitura de versões preliminares deste artigo, o que contribui decisivamente para o seu aperfeiçoamento até esta versão final.

1 Esse número foi reduzido a partir de 2008. Para mais detalhes, ver item 1.1.

2 De 2004 a 2006, a experiência foi realizada no período noturno. De 2007 a 2009, no período matutino.

3 Ao longo deste texto, a expressão aula expositiva será utilizada algumas vezes. Como se percebe pelo já exposto, ela nem sempre significará aula exclusivamente expositiva. Em alguns momentos, o que se quer dizer com a expressão é, na verdade, aula para grandes audiências. Como este texto tem por objetivo narrar a nossa experiência em aulas de seminários, não será possível discutir as possíveis variações metodológicas nessas aulas para grandes audiências. Contudo, é importante deixar claro que aqui não se pressupõe que, para essas aulas para grandes audiências, a única abordagem didática possível seja a exposição pura e simples de conteúdos programáticos, sem debates. Fomentar a participação dos alunos nesse tipo de aula também é possível e viável. Como se afirmou no texto, é isso o que se procura fazer no curso de direitos fundamentais, seja nas aulas com mais público, seja naquelas com grupos menores.

4 Para os fins deste texto, portanto, turma é o conjunto básico de alunos, cujo tamanho é definido pela própria faculdade. Grupos, por sua vez, são as subdivisões dessa turma para fins de seminário, cujo tamanho é definido pelo professor. Em algumas aulas - nas chamadas aulas expositivas -, os alunos de uma turma estão todos presentes em uma sala maior (a sala regular de aula); em outras - nas aulas de seminários - os alunos dirigem-se a salas menores, onde se reúnem apenas os alunos e os monitores de cada grupo.

5 Essa falta de tempo é, na verdade, muito mais dramática, já que a conta acima é baseada em uma aula de uma hora na qual há apenas debates e na qual apenas os alunos falam. Como uma parte da aula é sempre ocupada pela exposição do texto e como os monitores também intervêm no debate, é possível imaginar que, na verdade, se houvesse cinquenta alunos na sala, sobraria muito menos de um minuto para cada estudante.

6 Essa variação tem dois objetivos simples. Em primeiro lugar, é comum que outras disciplinas também tenham aulas de seminários e que os grupos sejam organizados com base na ordem alfabética dos primeiros nomes dos estudantes. Assim, é possível que, ao longo de todo o curso de Direito, os estudantes com prenomes que começam com a mesma letra estejam sempre nos mesmos grupos. Para quebrar um pouco essa rotina, pode às vezes valer a pena organizar os grupos com base nos sobrenomes. Além disso, organizar os grupos por ordem de sobrenome pode ser uma maneira de evitar uma situação a qual pode dificultar a memorização dos nomes dos alunos por parte dos monitores: a presença de várias pessoas com o mesmo prenome no mesmo grupo (já ocorreu de haver dez pessoas com o mesmo prenome em um grupo de vinte)

7 Em muitos casos, é possível afirmar que essa dinâmica de trabalho também reproduz melhor o ambiente profissional de diversas carreiras jurídicas.

8 Ver Anexo 1.

9 Embora não seja aqui nossa intenção elaborar hipóteses válidas para todos os ramos do direito, parece-nos que o raciocínio exposto acima é válido para além do âmbito dos direitos fundamentais. Não nos parece ser necessário que todos os menores detalhes de direito civil, direito penal, direito tributário, direito comercial ou de direito do trabalho, entre outros, tenham que ser abordados em sala de aula para que o aluno esteja preparado para solucionar casos no futuro. Parece-nos, além disso, que a insistência nessa visão detalhista - focada na exposição e na necessidade de decorar conteúdos - tem ainda duas outras consequências indesejáveis. Em primeiro lugar, ela cria uma expectativa no aluno que geralmente é frustrada, já que simplesmente impossível abordar tudo em sala de aula; quando isso ocorre, é comum que 
o estudante imagine que deixou de aprender algo que deveria ter aprendido em sala de aula. Em segundo lugar, essa insistência na exaustão do conteúdo programático em sala de aula gera um congestionamento das grades curriculares dos cursos de Direito, com intermináveis aulas expositivas da mesma disciplina ao longo de vários semestres. Em suma: o que se costuma fazer nos cursos tradicionais é decorar, em vez de desenvolver a capacidade de reflexão. Se optarmos por fomentar esta última, torna-se então desnecessário, no caso dos direitos fundamentais, passar por todos os dispositivos do art. $5^{\circ}$ da Constituição.

10 Em 2004, por exemplo, discutimos a ADI 3.105, sobre direitos adquiridos; em 2005, ano do referendo sobre o desarmamento, usamos as ADI 3.137 e 3.198, com suas petições iniciais, pareceres e amici curiae, que versavam sobre o tema; também em 2005, utilizamos a ADPF 54, sobre o aborto de fetos anencéfalos, proposta naquele mesmo ano.

11 Essa situação é também conhecida como o "fenômeno das fichas amareladas". Esse nome ilustra a situação em que o professor utiliza, como apoio para a sua aula, anotações feitas em pequenas fichas cartonadas que, por terem sido feitas há muito tempo, tornaram-se amareladas.

12 No caso de uma ADI, isso significaria um voto pela constitucionalidade dos dispositivos impugnados.

13 Para mais detalhes acerca do ponto de partida teórico que orienta o curso, ver: SILVA, Virgílio Afonso da. Direitos fundamentais: conteúdo essencial, restrições e eficácia. São Paulo: Malheiros, 2009.

14 Sobre a proporcionalidade, ver, entre outros: ÁVILA, Humberto Bergmann. "A distinção entre princípios e regras e a redefinição do dever de proporcionalidade”, Revista de Direito Administrativo, n. 215, p. 151-79, 1999; MENDES, Gilmar Ferreira. "O princípio da proporcionalidade na jurisprudência do Supremo Tribunal Federal: novas leituras", Repertório IOB de jurisprudência: tributário, constitucional e administrativo, n. 14, p. 361-72, 2000; SILVA, Virgílio Afonso da. "O proporcional e o razoável". Revista dos Tribunais, n. 798, p. 23-50; STEINMETZ, Wilson Antônio. Colisão de direitos fundamentais e princípio da proporcionalidade. Porto Alegre: Livraria do Advogado, 2001.

15 Qual é exatamente esse perfil é algo que ficará mais claro ao longo do texto, especialmente a partir da descrição das tarefas desempenhadas pelos monitores.

16 O que acaba de ser descrito corresponde ao modelo atual de seleção. Em anos anteriores, a equipe de monitores era formada também por alunos de graduação. Mas o processo de seleção era exatamente o mesmo: de um lado, orientandos do docente; de outro, alunos de cursos de graduação por ele ministrados. Como o professor dava aulas tanto no curso de Direitos Fundamentais, que ocorre no segundo ano de graduação, quanto em alguns cursos do quinto ano, os monitores selecionados entre os alunos desses últimos não tinham um contato próximo e direto com os alunos cujas atividades eles coordenariam.

17 "Pautar o debate" não significa que ele deixe de ser um debate livre. Como será visto adiante, a liberdade do debate tem que ser conciliada com as finalidades pedagógicas e substanciais dos seminários. Por isso, em vários momentos é preciso intervir na discussão para que pontos importantes da matéria não sejam ignorados.

18 Dessa forma, evita-se um engessamento completo das monitorias, o que ocorreria se ao monitor fosse atribuído um papel de autômato, de alguém que simplesmente leia as perguntas e provocações decididas nas reuniões, mas evita-se também o equívoco oposto, que ocorre quando não há diálogo entre os monitores e, especialmente, entre os monitores e o professor, o que frequentemente gera uma situação em que cada monitor prepara sua aula sozinho, não havendo uniformidade, mínima que seja, no tratamento da matéria com os alunos. Um claro sintoma desse último problema é o fato de as provas escritas finais geralmente não incluírem nenhuma pergunta acerca de algo que tenha sido tratado em seminário, já que é comum que não se saiba ao certo o que foi discutido nessas aulas. A partir da nossa experiência, parece-nos não apenas possível, mas também desejável, que os debates de seminário sejam também objeto de perguntas na prova final do semestre. É possível porque se sabe o que foi debatido, porque há um núcleo comum que permeia os debates em todos os grupos; e é desejável porque isso afasta ainda mais a percepção, já mencionada (Parte 1), de que os seminários são uma atividade menos importante no processo de aprendizado (Parte 6).

19 A esse respeito, ver Parte 4.

20 Para mais informações: <cf. www.moodle.org>. É importante salientar que o Moodle é um sistema baseado no conceito de software livre e de código aberto, forma mais plural, democrática e comunitária de produção de softwares. 
Também nas aulas expositivas o uso de recursos eletrônicos está baseado em sistema operacional (Linux) e programa de apresentação de slides (OpenOffice) de distribuição gratuita.

21 Normalmente são reservados vinte minutos para cada dupla apresentar o caso a ser debatido. Esse tempo pode ser dividido da forma como a dupla quiser. É incentivada a interação entre a dupla, e não a simples divisão de dez minutos para cada.

22 Os alunos tendem a ter uma visão idealizada dos textos acadêmicos e das decisões judiciais. Valorizam e elogiam, por exemplo, grandes incursões históricas presentes nesses textos, mesmo que elas pouco contribuam para o debate, ou até mesmo fujam dele.

\section{Ver Parte 4.}

24 Esses perfis baseiam-se em dicotomias simples, como "leu ou não os textos", "presta ou não presta atenção no que os colegas dizem antes de intervir no debate", "fundamenta ou não as suas intervenções”, "respeita ou não a vez dos colegas", "aceita ou não argumentos contrários", "participa com regularidade ou é inconstante”, entre outras.

25 Após alguns anos de experiência, houve uma pequena mudança no significado de "participar dos debates do começo ao fim”. Nos primeiros anos de seminário, o professor assistia também às apresentações dos textos, que antecedem os debates. Em determinado momento, percebeu-se que a presença do professor às vezes deixava alguns expositores mais nervosos, o que poderia gerar uma desigualdade de tratamento, já que o professor não teria como assistir a todas as apresentações, porque elas acontecem simultaneamente em quatro ou cinco salas. Por isso, decidiu-se que seria melhor que o professor não assistisse às apresentações, apenas participasse dos debates.

26 Embora neste texto tenham sido narrados sobretudo os impactos positivos na formação dos alunos de graduação, parece-nos que a forma como organizamos nossos seminários pode também gerar impactos em outros âmbitos. Digno de nota aqui são os efeitos positivos na formação de novos acadêmicos. Muitos dos monitores têm como objetivo uma carreira docente, e a participação nessa experiência didática pode auxiliá-los em várias frentes, especialmente no que diz respeito à importância: (a) da postura em sala de aula; (b) do preparo prévio; (c) da abertura a debates e da fuga do modelo de professor que apenas expõe o que já está nos livros; (d) da importância dos casos práticos para o estudo do direito e para a atividade docente. Mas, para além desses eventuais resultados positivos em uma futura atividade docente, também uma futura atividade de pesquisa pode ser beneficiada por essa experiência, já que os monitores são forçados a conviver intensamente com a necessidade de leitura crítica, de não se curvar diante do argumento de autoridade, de compreender os pontos de vista e argumentos contrários, de sofisticar cada vez mais o seu argumento, entre outros.

\section{REFERÊNCIAS BIBLIOGRÁFICAS}

ÁVILA, Humberto Bergmann. A distinção entre princípios e regras e a redefinição do dever de proporcionalidade. Revista de Direito Administrativo, n. 215, p. 151-79, 1999.

MENDES, Gilmar Ferreira. O princípio da proporcionalidade na jurisprudência do Supremo Tribunal Federal: novas leituras. Repertório IOB de jurisprudência: tributário, constitucional e administrativo, n. 14, p. 361-72, 2000.

SILVA, Virgílio Afonso da. O proporcional e o razoável, Revista dos Tribunais, n. 798, p. 23-50. . Interpretação constitucional e sincretismo metodológico. In: SILVA, Virgílio Afonso da (Org.). Interpretação constitucional. São Paulo: Malheiros, 2005. p. 115-43.

. Direitos fundamentais: conteúdo essencial, restrições e eficácia. São Paulo: Malheiros, 2009.

STEINMETZ, Wilson Antônio. Colisão de direitos fundamentais e princípio da proporcionalidade. Porto Alegre: Livraria do Advogado, 2001. 
Largo São Francisco, 95 Sé - 01005-010 São Paulo - SP - Brasil vaslausp.br

Rua dos Ingleses, 309, $9^{\circ}$ andar Morro dos Inleses - 01329-000 São Paulo - SP - Brasil danielwei_cnlayahoo.com.br
Virgílio Afonso da Silva

MESTRE EM DIREITO DO ESTADO PELA UnIVERSIDAdE dE SÃo PaUlo (USP)

Doutor em diReito pela Universidade de Kiel (Alemanha)

LIVRE-DOCENTE EM DIREITO CONSTITUCIONAL PELA Universidade de São Paulo (USP)

PROFESSOR TITULAR DE DIREITO CONSTITUCIONAL NA Faculdade de Direito da Universidade de São Paulo (FDUSP)

\section{Daniel Wei Liang Wang}

MESTRE EM DIREITO CONSTITUCIONAL PELA Universidade de SÃo Paulo (USP) MESTRANDO EM FILOSOFIA E POLÍTICAS PÚBLICAS pela London School of Economics and Political Science 